\title{
Microwave Assisted Acid Digestion of Biomorphic Ceramic Obtained from Cedar Wood Infiltrated with $\mathrm{ZrO}_{2}$
}

\author{
Fuensanta Sánchez Rojas, Catalina Bosch Ojeda, José Manuel Cano Pavón \\ Department of Analytical Chemistry, Faculty of Sciences, University of Málaga, Málaga, Spain \\ E-mail:fsanchezr@uma.es \\ Received October 22, 2010; revised November 15, 2010; accepted November 17, 2010
}

\begin{abstract}
This work proposes the use of experimental design for optimization of microwave-assisted digestion of biomorphic $\mathrm{ZrO}_{2}$-ceramic. Cedar wood is used as template and it was infiltrated with $\mathrm{ZrO}_{2}$ via sol-gel process. XPS, SEM and XRD have been used to verify the effectiveness of the synthesis. The effects of different combination of acids in the digestion of this sample have been optimized taking as response the concentration of several metallic ions measured by ICP-MS.
\end{abstract}

Keywords: Cedar Wood, Microwave Digestion, ICP-MS, Metallic Ions, Experimental Design

\section{Introduction}

Sol-gel processing is a new technology that is being developed more quickly for the manufacture of ceramic and glasses. In the ceramics, this method allows the uniform and fine particle formation of high purity to relatively low temperatures. These dusts can be sintered next until obtaining to a high density with their corresponding good mechanical properties. In such techniques, the fundamental characteristic is the formation of an organometallic dissolution. The phase disperses "sol" becomes a rigid "gel", which, as well, is reduced until its final composition by means of diverse heat treatments. A key advantage of the process sol-gel is that the product the forms initially by means of this procedure of liquid phase can be roasted to lower temperatures, compared with those of the conventional processes for ceramics.

The aim of this work is to optimize a microwave acid digestion procedure for the determination of metals in biomorphic ceramic samples. Microwave radiation is widely used in modern chemistry and technology as a source of energy for intensification of physicochemical processes. Microwave-assisted digestion has clear advantages over the traditional acid digestion using convective heating systems in terms of recovery, precision, short time needed (minutes) to perform decomposition of the sample, direct heating of samples and reagents (the vessels are only indirectly heated by the hot solution), minimal contamination and looses of volatile elements. It reduces the possibility of cross contamination and the consumption of reagents. The use of small amounts of reagents decreases the blank signal. The combination of different acids, such as $\mathrm{H}_{2} \mathrm{SO}_{4}, \mathrm{HNO}_{3}, \mathrm{HCl}$ and $\mathrm{HF}$ is a very frequent method for preparing samples before their quantitative elemental analysis.

The association of factorial design [1] and microwave-assisted [2-6] digestion can contribute to accelerate the pre-treatment step, improving the accuracy of the results. On the other hand, ICP-MS is an ideal technique for determining elements, with rapid data acquisition and low detection limits. This work proposes the use of experimental design for optimization of microwave-assisted digestion of biomorphic $\mathrm{ZrO}_{2}$-ceramic [7-13].

\section{Experimental}

\subsection{Instrumentation}

A Lenton Tube furnace, model LTF 16/180, was employed for the synthesis of biomorphic ceramics.

X-ray photoelectron spectroscopy (XPS) analysis was performed with a Physical Electronics 5700 instrument with a $\mathrm{Mg} \mathrm{K} \alpha \mathrm{X}$-ray excitation source $(\mathrm{h} v=1253.6 \mathrm{eV})$; binding energies (BE) were determined with respect to the position of the $\mathrm{C} 1 \mathrm{~s}$ peak at $284.5 \mathrm{eV}$. The residual pressure in the analysis chamber was maintained below $133 \times 10^{-9} \mathrm{~Pa}$ during data acquisition.

Scanning electronic microscopy (SEM) JEOL, Model SM-6490LV was used to obtain the micrographs shown 
in Figure 1 and semi-cuantitative analysis shown in Table 1.

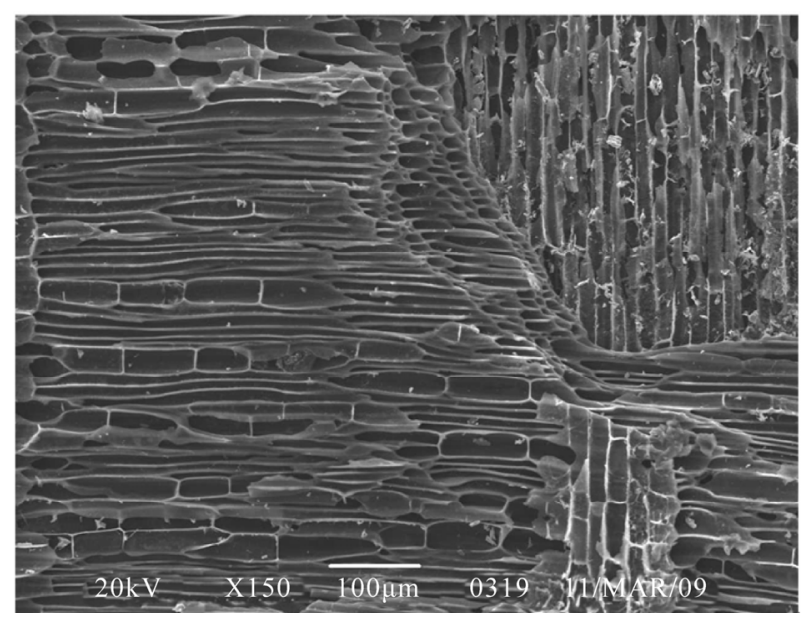

(a)

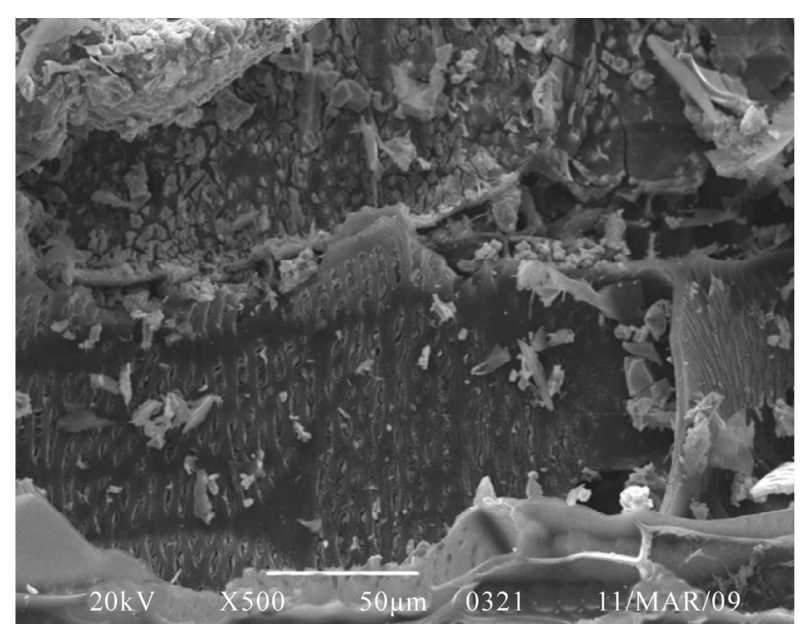

(b)

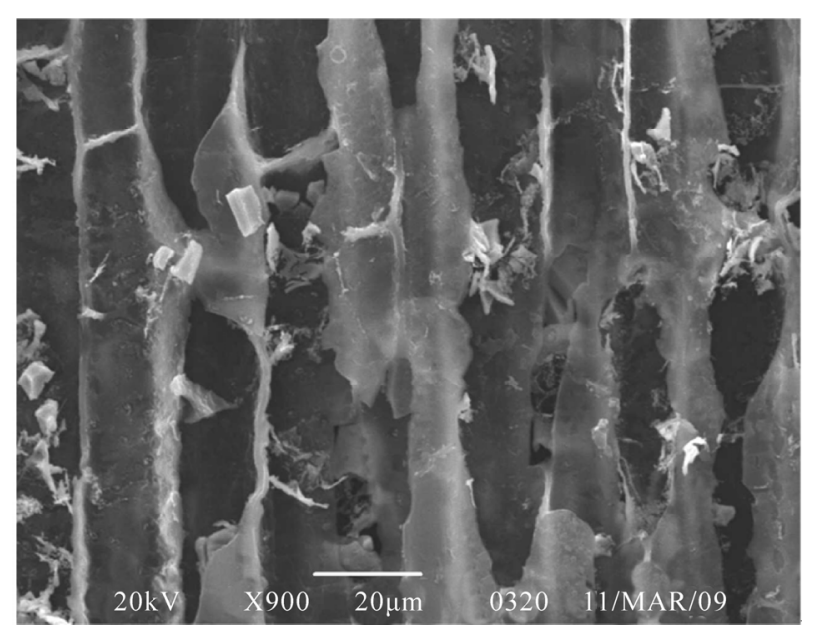

(c)

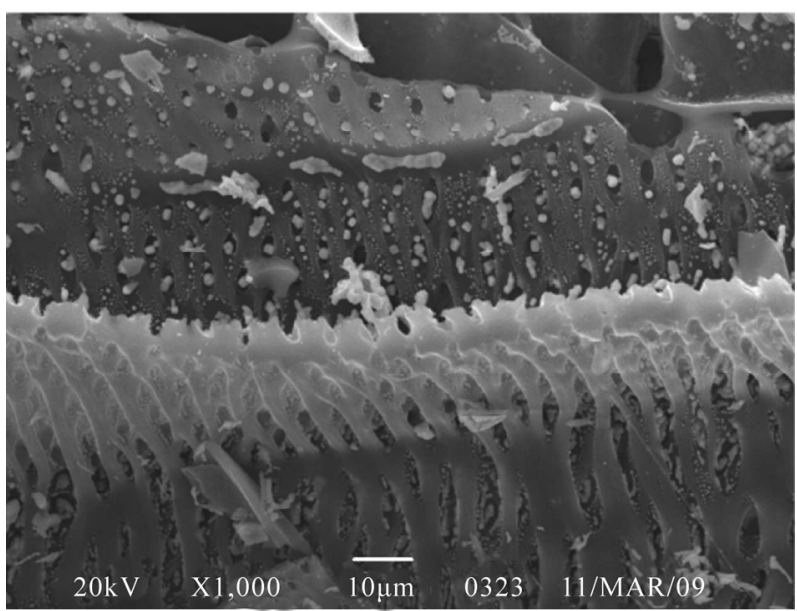

(d)

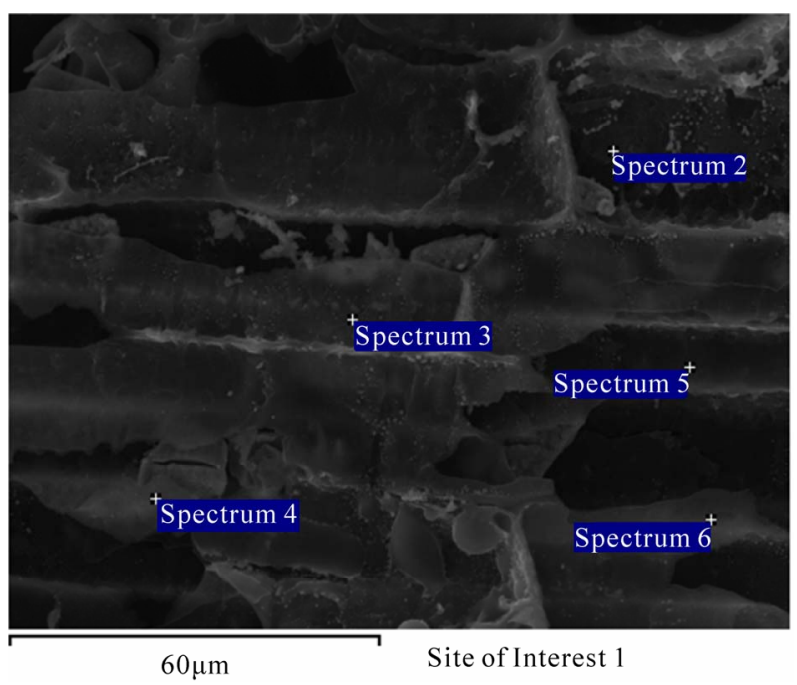

(e)

Figure 1. Micrographs of biomorphic ceramic obtained with SEM at different magnification a) $\times 150$, scale $1: 10 \mathrm{\mu m}$; b) $\times 500$, scale $1: 50 \mu \mathrm{m}$; c) $\times 900$, scale $1: 20 \mu \mathrm{m}$; d) $\times 1000$, scale 1: $10 \mu \mathrm{m}$; e) Site of interest for results showed in Table 1.

Table 1. Semi quantitative analysis made from Figure 1(e).

\begin{tabular}{cccccc}
\hline Espectrum & $\mathrm{C}$ & $\mathrm{O}$ & $\mathrm{Ca}$ & $\mathrm{Zr}$ & Total \\
\hline Espectrum (2) & 73.98 & & 3.71 & 22.31 & 100.00 \\
Espectrum (3) & 67.94 & 5.58 & 13.03 & 13.45 & 100.00 \\
Espectrum (4) & 87.26 & 4.40 & & 8.35 & 100.00 \\
Espectrum (5) & 88.04 & 3.80 & & 8.16 & 100.00 \\
Espectrum (6) & 93.81 & & & 6.19 & 100.00 \\
Máx. & 93.81 & 5.58 & 13.03 & 22.31 & \\
Min. & 67.94 & 3.80 & 3.71 & 6.19 & \\
\hline
\end{tabular}


Powder patterns were collected on a X'Pert Pro MPD automated diffractometer equipped with a $\mathrm{Ge}(111)$ primary monochromator (strictly monochromatic $\mathrm{CuK} \alpha_{1}$ radiation) and an $\mathrm{X}^{\prime}$ Celerator detector. The overall measurement time was approximately $30 \mathrm{~min}$ per pattern to have very good statistic over the 2 range of $10^{\circ}-70^{\circ}$ with $0.017^{\circ}$ step size. The patterns were identified using the PDF (Powder Data File).

A Panasonic (National) microwave oven, model NN8507, and a Parr Microwave Acid Digestion Bomb, model 4782, were used for sample digestion. The bombs were cleaned before use with $10 \%(\mathrm{v} / \mathrm{v}) \mathrm{HNO}_{3}$ for 1 day followed by repeated rinsing with water.

The measurements of $\mathrm{Zr}, \mathrm{Cu}, \mathrm{Fe}, \mathrm{Mg}$ and $\mathrm{Ni}$ elements were performed on a PerkinElmer ELAN DRCe ICP-MS quadrupole spectrometer. The samples were introduced into the ICP-MS via a RytonTM cross-flow nebulizer (PerkinElmer), Scott spray chamber (PerkinElmer) and Cetac ASX-510 autosampler. The sample transport from the autosampler to the nebulizer was established by a peristaltic pump. The operating parameters of the spectrometer are summarized in Table 2.

\subsection{Reagents}

Analytical reagent grade chemicals were used throughout. Sol was prepared from zirconium $n$-propoxide (ZNP) $\mathrm{Zr}\left[\mathrm{O}\left(\mathrm{CH}_{2}\right)_{2} \mathrm{CH}_{3}\right]_{4}$ (Merck) for infiltration into the porous biological templates. Prior to hydrolysis, ZNP was modified with acetic acid ( $\mathrm{HAc})$ in a molar ratio of $1: 4$ to reduce reactivity with $\mathrm{H}_{2} \mathrm{O}$.

Standard $1000 \mu \mathrm{g} \cdot \mathrm{mL}^{-1} \mathrm{Zr}(\mathrm{IV}), \mathrm{Cu}(\mathrm{II}), \mathrm{Ni}(\mathrm{II}), \mathrm{Fe}(\mathrm{III})$ and $\mathrm{Mg}(\mathrm{II})$ solutions (Fluka) were used. Standards of working strength were made by appropriate dilution as required, immediately prior to use. Water was deionised with a Milli-Q system. Concentrated acid $\mathrm{HCl}$, HF, $\mathrm{H}_{2} \mathrm{SO}_{4}$ and $\mathrm{HNO}_{3}$ (Merck) were used for digestion of the samples.

\subsection{Synthesis}

Based on previously described synthesis [14] in the literature, rectangular specimens of native cedar of dimensions $(3.5 \times 3.5 \times 1) \mathrm{cm}^{3}$ were dried $\left(130^{\circ} \mathrm{C} / 24 \mathrm{~h}\right)$ and later subjected to vacuum infiltration for $2 \mathrm{~h}$ with $\mathrm{ZrO}_{2}$-sol. The specimens were dried at $110^{\circ} \mathrm{C}$ for $1 \mathrm{~h}$ in air to form the gel in the wood cells after infiltration. A schematic diagram of the device used for the vacuum infiltration is shown in Figure 2.

The infiltration and drying process was repeated for three times. Multiple infiltrations were used to increase the content of the $\mathrm{ZrO}_{2}$ precursor in the specimen. After the infiltration steps, the cedar samples were pyrolyzed at
Table 2. ICP-MS operating parameters used for element determination.

\begin{tabular}{cc}
\hline RF power & $1100 \mathrm{~W}$ \\
\hline Nebulizer gas flow & $0.92 \mathrm{~L} \cdot \mathrm{min}^{-1}$ \\
Plasma gas flow & $15 \mathrm{~L} \cdot \mathrm{min}^{-1}$ \\
Auxiliary gas flow & $1.2 \mathrm{~L} \cdot \mathrm{min}^{-1}$ \\
Nebulizer & Cross-flow \\
Spray chamber & Scott type \\
Cones & Nickel \\
Lens voltage & $6.5 \mathrm{~V}$ \\
Analog stage voltage & $-1800 \mathrm{~V}$ \\
Pulse stage voltage & $850 \mathrm{~V}$ \\
Sweep/reading & 20 \\
Reading/replicate & 1 \\
Replicate & 3 \\
Scan mode & Peak hopping
\end{tabular}

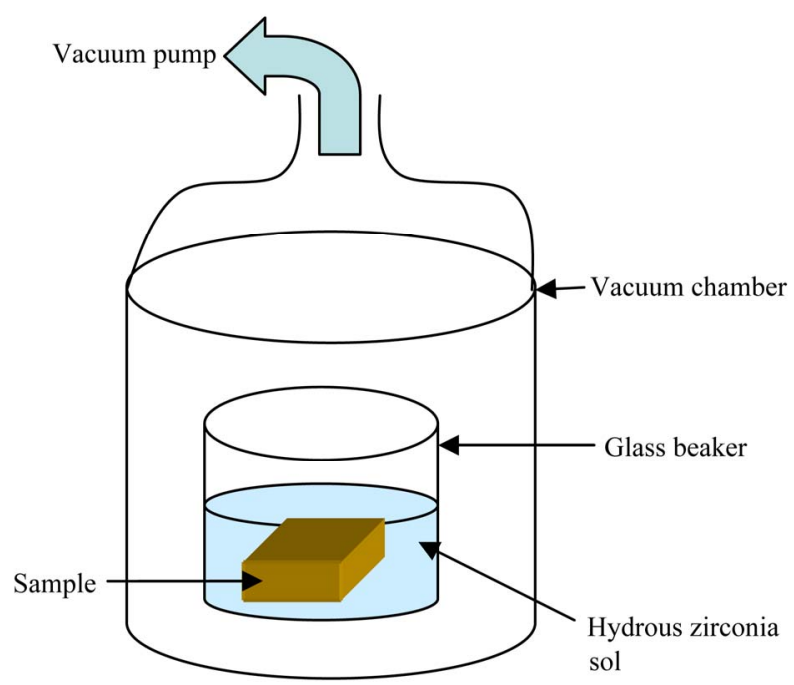

Figure 2. Schematic drawing of the experimental set-up for the vacuum infiltration process.

$800^{\circ} \mathrm{C}$ for $1 \mathrm{~h}$ in $\mathrm{Ar}$ atmosphere in order to decompose cellulose, hemicellulose, and lignin into carbon. After repeated infiltration steps, the specimens were annealed up to $1200^{\circ} \mathrm{C}$ during $3 \mathrm{~h}$ (temperature ramp $5^{\circ} \mathrm{C} / \mathrm{min}$ up to $1200^{\circ} \mathrm{C}$ ).

The infiltration/drying process was repeated up to three times to increase the $\mathrm{ZrO}_{2}$ content in the biomorphic samples. The infiltration/annealing processing are described by the schematic diagram in Figure 3 [13]. 


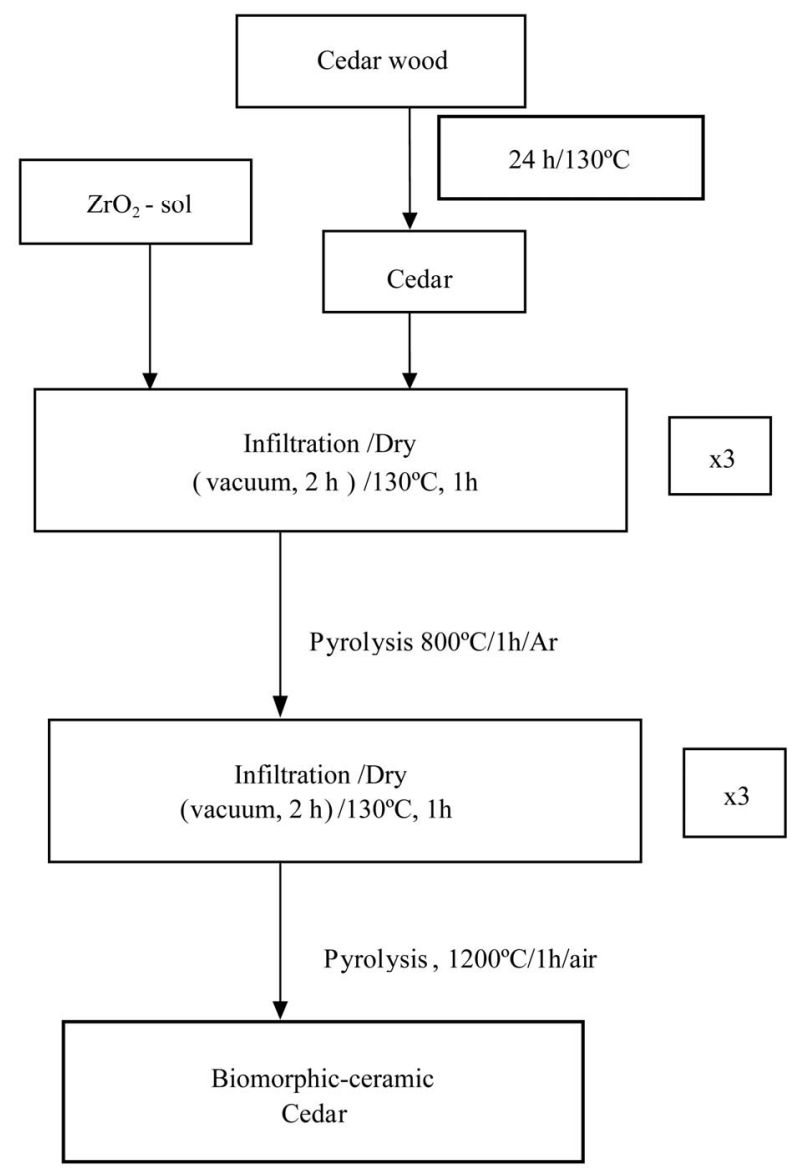

Figure 3. Flow chart for the manufacturing of biomorphic $\mathrm{ZrO}_{2}$ cedar.

\subsection{Microwave-Assisted Pressure Digestion with Acids}

In a preliminary step, ten samples of $10 \mathrm{mg}$ each one were weighed accurately and then different acid mixtures (combination of binary and ternary mixtures of $\mathrm{HCl}, \mathrm{HF}$, $\mathrm{HNO}_{3}$ and $\mathrm{H}_{2} \mathrm{SO}_{4}$ ) were added to the digestion vessels and were treated for 2 min to maximum power. The dissolutions obtained were completely transferred into a 25 $\mathrm{mL}$ calibrated flasks and diluted to volume with water. Then, the optimum mixture of acids was obtained by means of the ICP-MS and taking as response variable the concentrations of several ions to select the better mixture of acids. From these data we concluded the best acid mixture was $\left(\mathrm{H}_{2} \mathrm{SO}_{4}+\mathrm{HF}\right)$.

Later, a $5^{2}$ multi-level factorial design with 25 runs (in duplicates) was developed in order to determine the influence of the factors and their interactions on the system. Two factors were studied: volumes of acids selected $\left(\mathrm{H}_{2} \mathrm{SO}_{4}\right.$ and $\left.\mathrm{HF}\right)$.

The sequence of the experiments carry out is shown in Table 3. The experimental data were processed making use of the STATGRAPHICS 5.1 plus program [15]. The significance of the effects was done by analysis of variance (ANOVA) and using $p$-value significance levels. This value represents the probability of the effect of a factor being due solely to random error. Thus, if the $p$-value is less than $5 \%$, the effect of corresponding factor is significant. The effects and significance of the variables in the microwave-assisted digestion system were evaluated using Pareto's charts.

\section{Results and Discussion}

\subsection{XPS Analysis}

XPS has been used for the study of the surface composition of the sample. For this study the biomorphic materials were powdered and homogenized in an agate mortar. Measurements were performed on samples mounted in a cup ( $1 \mathrm{~mm} \times 3.5 \mathrm{~mm}$, i.d.) and pressed manually.

XPS spectrum obtained is shown in Figure 4. Consequently, the performance of the synthesis of biomorphic ceramics can be evaluated approximately from these data.

The atomic concentration calculation is expressed as a percentage in a tabular form based on the area under the peak, multiplied by the sensitivity factor for each element, and provides a ratio of a single element to the sum of the others elements present [16] (Table 4). The error of the method is approximately of $10 \%$.

\subsection{XRD Analysis}

The identification is based on PDF data base. The content of amorphous phase in the sample is high as can be seen from Figure 5, due to the background curvature between $20^{\circ}-30^{\circ} 2$ theta and $40^{\circ}-50^{\circ} 2$ theta. From this figure we can conclude the sample is especially monoclinic $\mathrm{ZrO}_{2}$ (PDF number 01-086-1450), although the sample shows in less proportion tetragonal phase of the same oxide (PDF number 01-080-0784).

\subsection{Sample Dissolution}

Factorial design approach is an useful tool to establish and improve analytical procedures. Although it seems more complex than the univariate procedure from the operative point of view, it is advantageous because it makes use of fewer experiments and provides important information on interactions among the studied variables $[17,18]$. A multi-level full factorial $5^{2}$ with 25 runs was carried out in order to determine the main factors of the microwave-assisted biomorphous $\mathrm{ZrO}_{2}$-ceramic diges- 
Table 3. Design matrix and the results for $\mathrm{Zr}, \mathrm{Cu}, \mathrm{Fe}, \mathrm{Mg}$ and Ni concentration.

\begin{tabular}{|c|c|c|c|c|c|c|c|}
\hline Experiment & Vol. $\mathrm{H}_{2} \mathrm{SO}_{4}(\mathrm{~mL})$ & Vol. HF (mL) & {$[\mathrm{Zr}](\mathrm{mg} / \mathrm{g})$} & {$[\mathrm{Cu}](\mathrm{mg} / \mathrm{g})$} & {$[\mathrm{Fe}](\mathrm{mg} / \mathrm{g})$} & {$[\mathrm{Mg}](\mathrm{mg} / \mathrm{g})$} & {$[\mathrm{Ni}](\mathrm{mg} / \mathrm{g})$} \\
\hline 1 & 2 & 4 & 411.8 & 1.9 & 1.8 & 7.6 & 0.7 \\
\hline 2 & 5 & 4 & 672.2 & 3.6 & 2.5 & 9.6 & 1.4 \\
\hline 3 & 4 & 4 & 469.7 & 2.1 & 1.6 & 12.3 & 1.2 \\
\hline 4 & 5 & 2 & 417.0 & 3.0 & 2.5 & 9.4 & 1.2 \\
\hline 5 & 4 & 5 & 391.4 & 2.7 & 2.7 & 9.4 & 1.3 \\
\hline 6 & 3 & 6 & 626.9 & 2.4 & 1.6 & 13.0 & 1.2 \\
\hline 7 & 2 & 5 & 631.0 & 1.6 & 1.7 & 10.0 & 1.3 \\
\hline 8 & 3 & 5 & 555.3 & 1.8 & 2.1 & 8.2 & 1.0 \\
\hline 9 & 2 & 3 & 566.8 & 1.5 & 1.0 & 10.1 & 0.7 \\
\hline 10 & 6 & 5 & 531.7 & 4.5 & 2.0 & 7.7 & 2.0 \\
\hline 11 & 3 & 3 & 387.8 & 2.0 & 1.6 & 7.7 & 0.8 \\
\hline 12 & 3 & 2 & 518.6 & 2.2 & 1.7 & 34.2 & 1.1 \\
\hline 13 & 6 & 4 & 531.6 & 4.0 & 1.4 & 14.0 & 1.7 \\
\hline 14 & 5 & 6 & 766.6 & 3.2 & 2.0 & 14.1 & 1.5 \\
\hline 15 & 2 & 6 & 548.2 & 1.4 & 4.0 & 10.3 & 0.8 \\
\hline 16 & 5 & 5 & 692.8 & 3.3 & 1.3 & 13.5 & 1.5 \\
\hline 17 & 2 & 2 & 468.0 & 1.2 & 1.5 & 8.9 & 0.6 \\
\hline 18 & 6 & 2 & 685.8 & 4.1 & 1.4 & 12.6 & 1.8 \\
\hline 19 & 4 & 3 & 575.9 & 2.2 & 1.4 & 10.0 & 1.0 \\
\hline 20 & 4 & 2 & 536.5 & 2.3 & 1.2 & 8.3 & 1.0 \\
\hline 21 & 6 & 3 & 502.7 & 3.5 & 1.5 & 11.8 & 1.6 \\
\hline 22 & 3 & 4 & 619.8 & 1.8 & 1.3 & 10.0 & 0.9 \\
\hline 23 & 6 & 6 & 588.4 & 3.0 & 2.2 & 12.6 & 1.5 \\
\hline 24 & 5 & 3 & 558.0 & 2.4 & 1.6 & 12.3 & 1.2 \\
\hline 25 & 4 & 6 & 831.4 & 2.1 & 1.8 & 15.4 & 1.1 \\
\hline
\end{tabular}

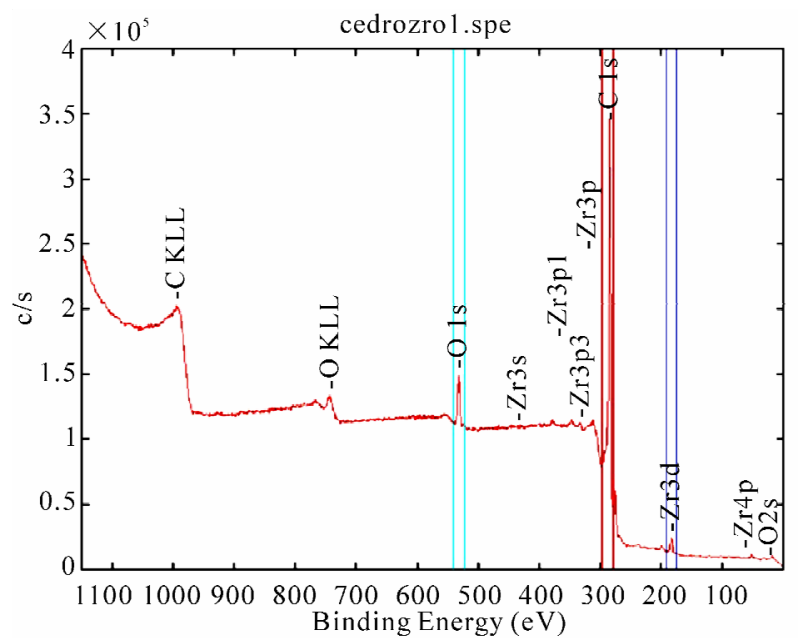

(a)

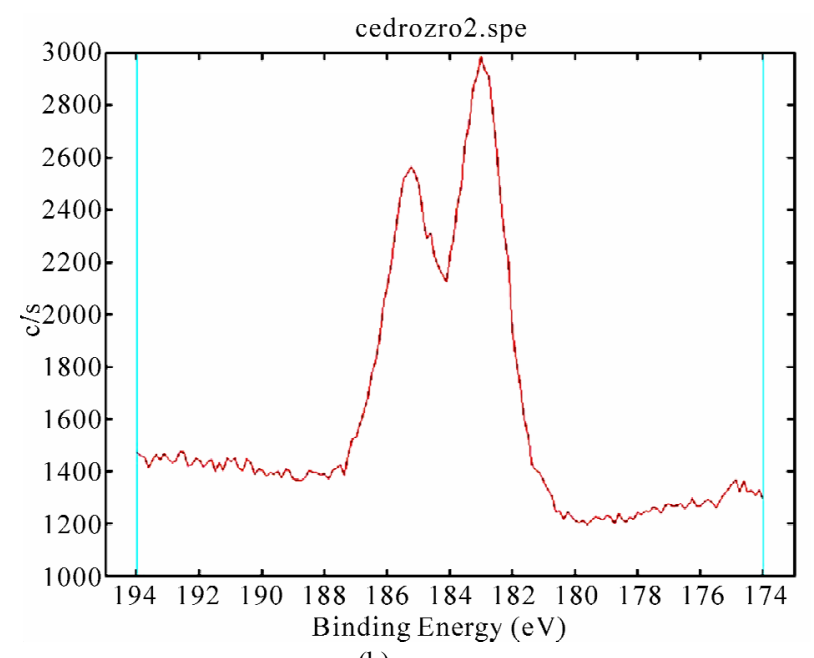

(b)

Figure 4. XPS spectrum for biomorphic ceramic from cedar wood a) survey b) $\mathrm{Zr} \mathrm{d}_{5 / 2}(183.8 \mathrm{eV})$. 
Counts

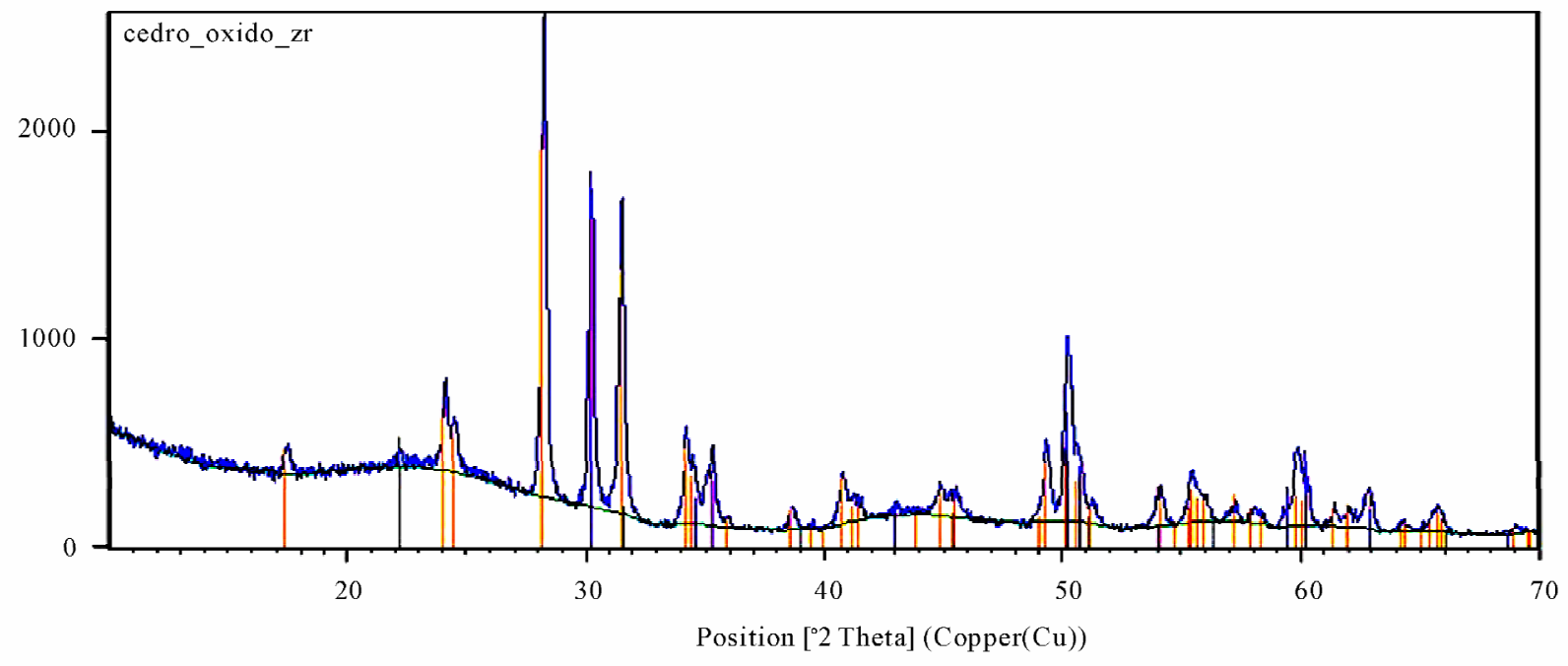

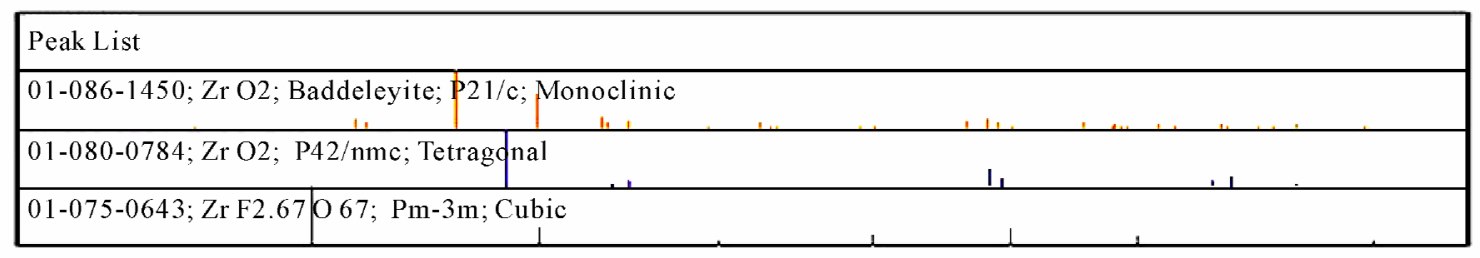

(a)

Counts

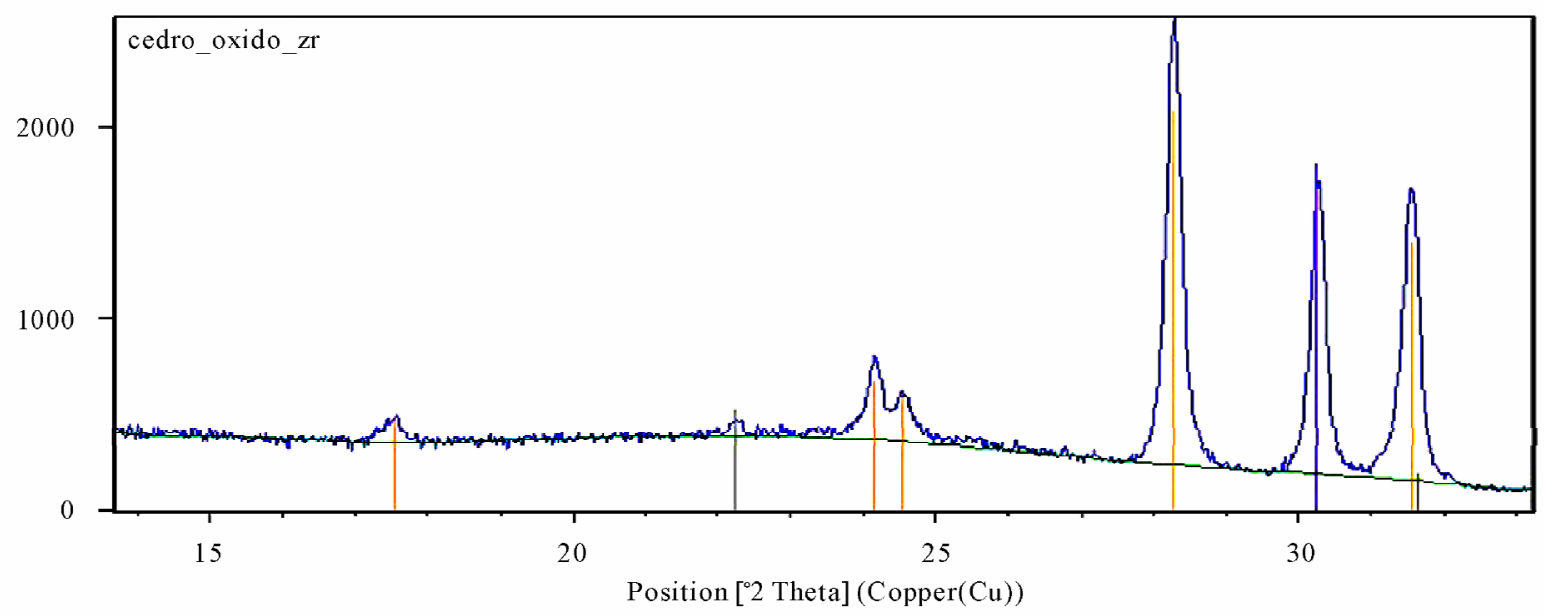

\begin{tabular}{|l|l|}
\hline Peak List & \\
\hline 01-086-1450; Zr O2; Baddeleyite; P2 1/c; Monoclinic & \\
\hline $01-080-0784 ;$ Zr O2; P42/nmc; Tetragonal & \\
\hline $01-075-0643 ; Z r$ F2.67 O 67; Pm-3m; Cubic & \\
\hline
\end{tabular}

(b)

Figure 5. XRD spectrum for biomorphic ceramic from cedar wood (a) between $10^{\circ}-70^{\circ} 2$ theta (b) Amplification between $15^{\circ}$ $-35^{\circ} 2$ theta. 
tion. The results of the ANOVA carried out on the data given in Table 3 are shown in Table 5.

The two-order effect combined Pareto charts $(\mathrm{P}=95 \%)$ were obtained for the two factors considered (Figure 6). After the analysis of the results, it was observed that the studied variables have no significant effects for $\mathrm{Mg}$ however significant effects were demonstrated for $\mathrm{HF}$ volume in the case of $\mathrm{Zr}, \mathrm{Fe}$ and $\mathrm{Ni}$ and $\mathrm{H}_{2} \mathrm{SO}_{4}$ volume in the case of $\mathrm{Cu}$ and $\mathrm{Ni}$.

\subsection{Comparison of Samples}

Also, we have made the comparison of the content of ions in samples of biomorphic ceramics of cedar and oak, and of cedar and pine. To carry out this comparison have employed a statistical procedure designed for to compare two sets of data, in our case concentrations of a certain

Table 4. Analysis of biomorphic ceramic by XPS.

\begin{tabular}{ccccc}
\hline \multirow{2}{*}{ Element } & \multirow{2}{*}{$\begin{array}{c}\text { Area } \\
\text { (cts-eV/s) }\end{array}$} & \multirow{2}{*}{$\begin{array}{c}\text { Sensitivity } \\
\text { factor }\end{array}$} & \multicolumn{2}{c}{ Concentration (\%) } \\
\cline { 4 - 5 } & & & Atomic & Mass \\
\hline $\mathrm{C} 1 s$ & 131082 & 7.439 & 93.65 & 89.15 \\
$\mathrm{O} 1 s$ & 20606 & 18.619 & 5.88 & 7.46 \\
$\mathrm{Zr} 3 d$ & 5675 & 63.731 & 0.47 & 3.4 \\
\hline
\end{tabular}

Table 5. P-value for data analysis given in Table $\mathbf{3}$ for metal ions concentration.

\begin{tabular}{cccccc}
\hline $\begin{array}{c}\text { Design } \\
\text { variable }\end{array}$ & $\begin{array}{c}\mathrm{P} \text {-Value } \\
(\mathrm{Zr})\end{array}$ & $\begin{array}{c}\mathrm{P} \text {-Value } \\
(\mathrm{Cu})\end{array}$ & $\begin{array}{c}\mathrm{P} \text {-Value } \\
(\mathrm{Fe})\end{array}$ & $\begin{array}{c}\mathrm{P} \text {-Value } \\
(\mathrm{Mg})\end{array}$ & $\begin{array}{c}\text { P-Value } \\
(\mathrm{Ni})\end{array}$ \\
\hline A: Vol. $\mathrm{H}_{2} \mathrm{SO}_{4}$ & 0.2754 & 0.000 & 0.7339 & 0.8055 & 0.000 \\
B: Vol. HF & 0.0341 & 0.7507 & 0.0335 & 0.6178 & 0.0451 \\
$\mathrm{AA}$ & 0.5789 & 0.1545 & 0.7738 & 0.4867 & 0.1106 \\
$\mathrm{AB}$ & 0.7541 & 0.5671 & 0.1417 & 0.4739 & 0.2814 \\
$\mathrm{BB}$ & 0.1950 & 0.4585 & 0.2498 & 0.1331 & 0.6803 \\
\hline
\end{tabular}

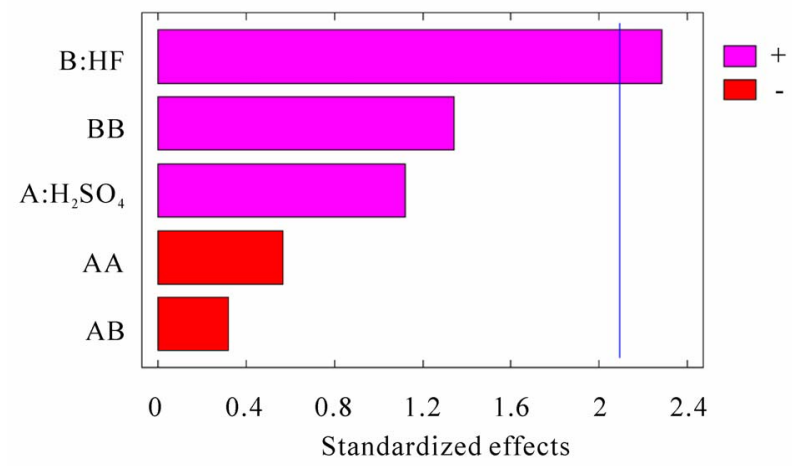

(a)

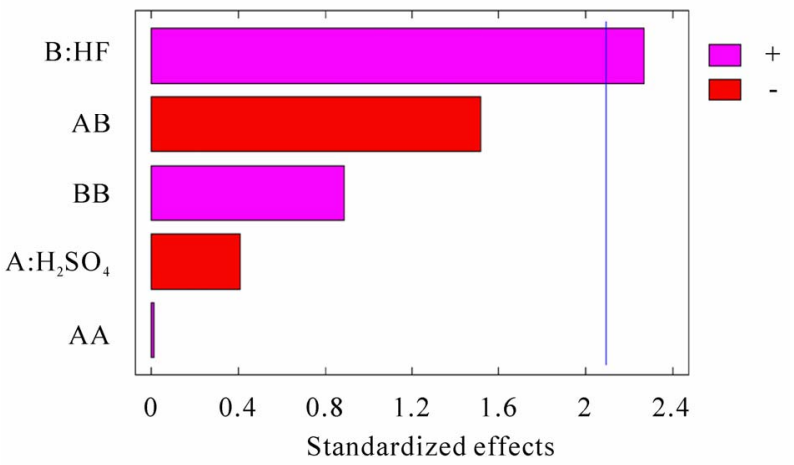

(b)

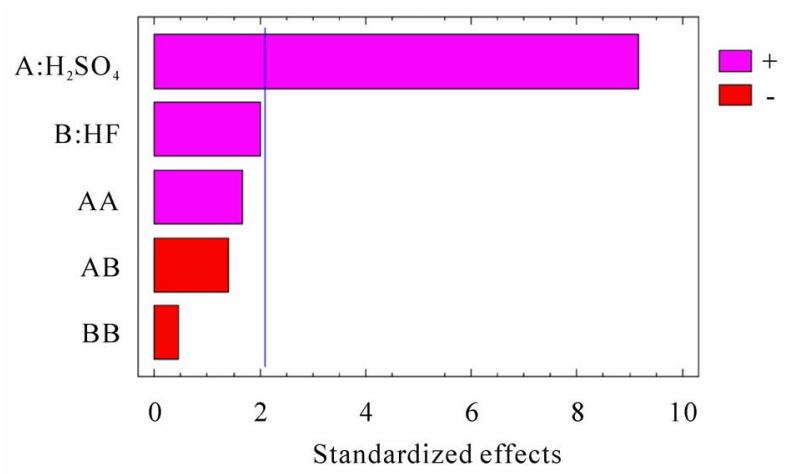

(c)

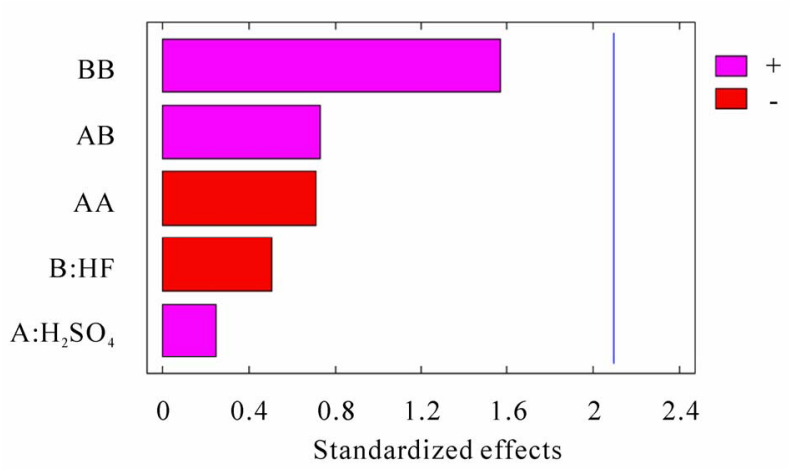

(d)

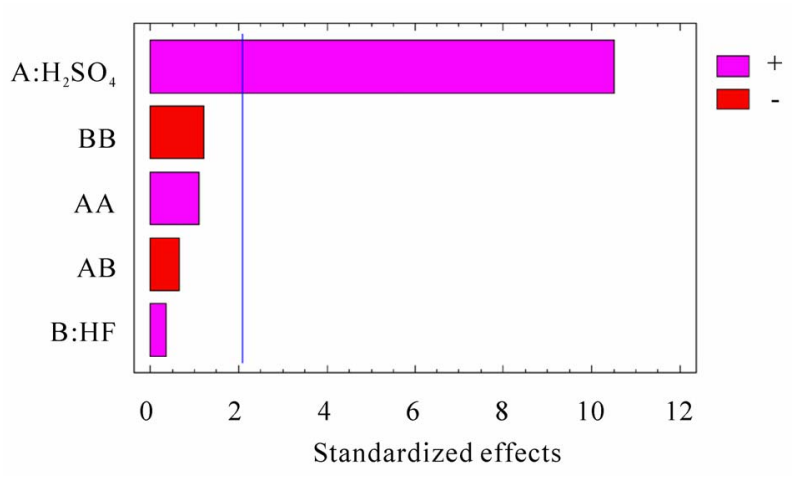

(e)

Figure 6. Pareto's charts for a) Zr; b) Fe; c) Ni; d) Mg; e) Cu. 

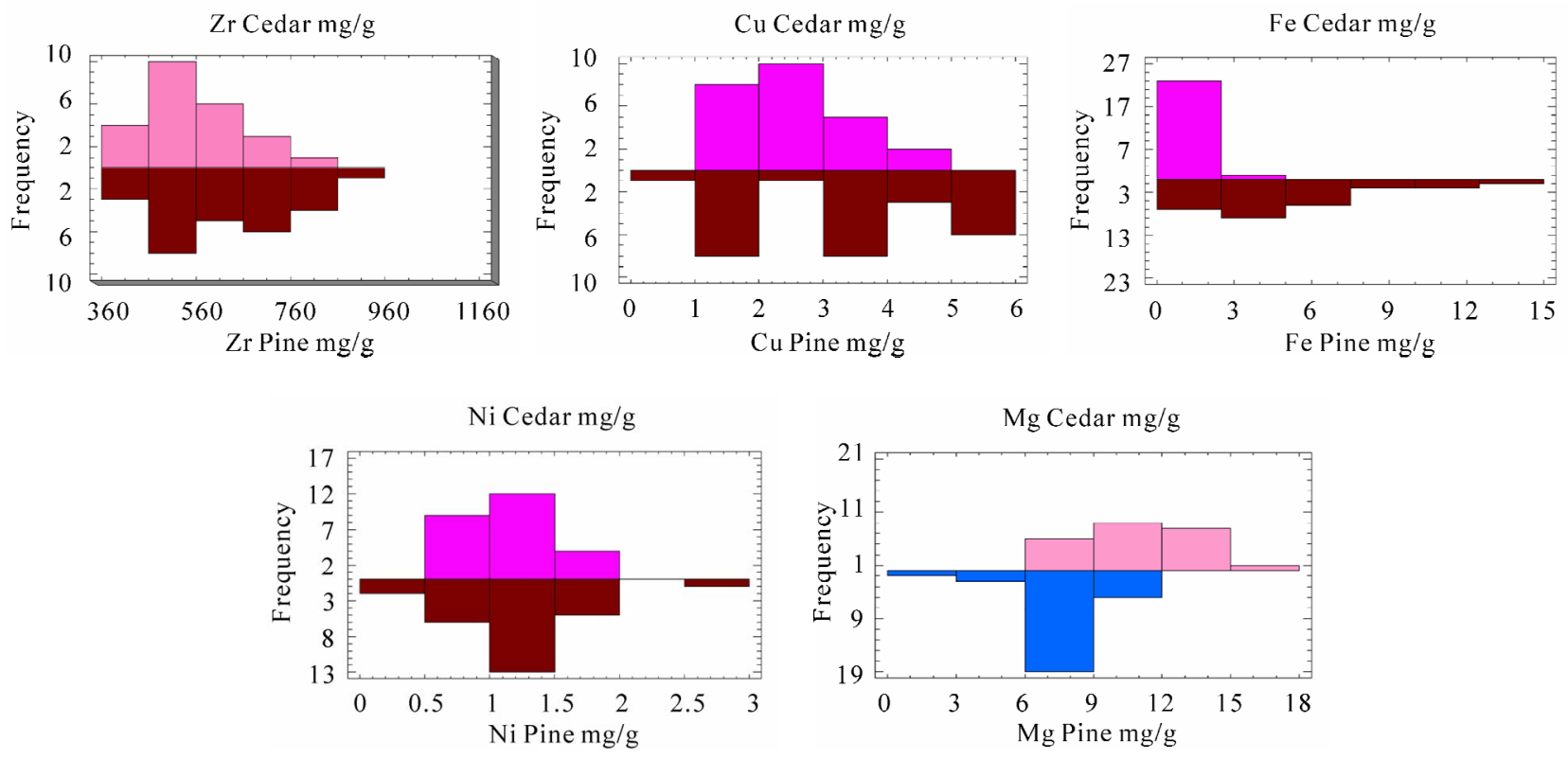

(a)
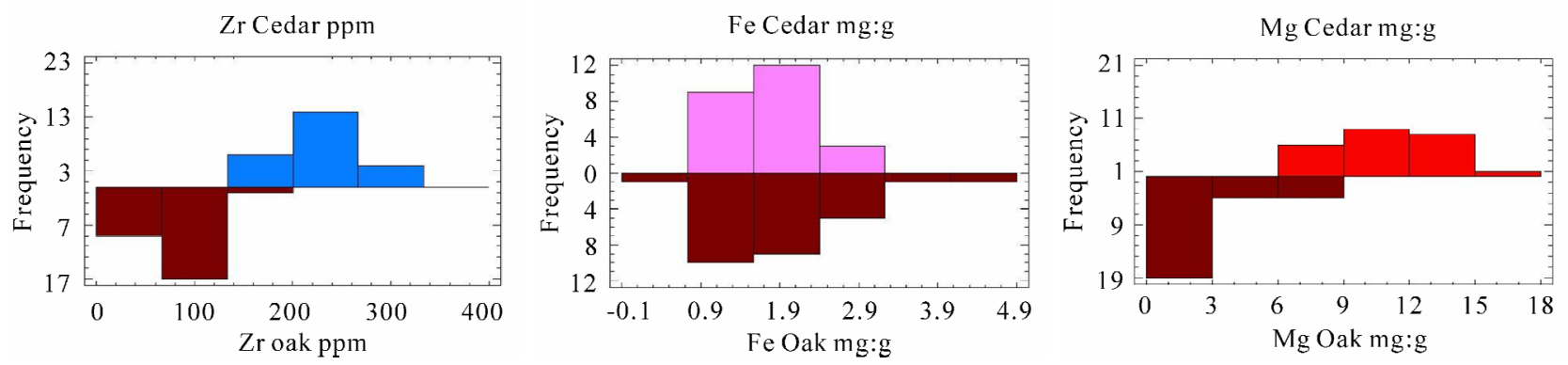

(b)

Figure 7. Comparison of ion contents from different biomorphic ceramic samples a) cedar-pine b) cedar-oak.

ion in two biomorphic materials synthesised in the same conditions whose only difference is the employed wood as precursor (cedar, oak and pine) and the infiltrant agent (zirconium oxichloride for the oak and zirconium $n$-propoxide for the cedar and pine).

The above-mentioned procedure calculates statistical data and it gives several charts for every shows. In addition executes several tests to determine if there are statistically significant differences between two samples.

Below the $\mathrm{F}$ test is made to compare the variances of the two samples. Additionally intervals or confidence limits are established for every standard deviation as well as for the reason of the variances. In addition are compared also the content of ions specific to the wood as are: $\mathrm{Mg}, \mathrm{Fe}, \mathrm{Ni}$ and $\mathrm{Cu}$. The results obtained are shown in Figure 7.

\section{Conclusions}

Different acid mixtures were tested for the samples digestion processes $\left(\mathrm{HCl}, \mathrm{HNO}_{3}, \mathrm{H}_{2} \mathrm{SO}_{4}, \mathrm{HF}\right)$. Of all of them the mixture $\left(\mathrm{H}_{2} \mathrm{SO}_{4}+\mathrm{HF}\right)$ was selected in order to obtain maximum concentration of the ions.

Differences on $\mathrm{Zr}$ contents in two ceramics (cedar and oak) can be due because synthesis have been made from different templates and different reagents to obtain $\mathrm{ZrO}_{2}$ sol-gel (zirconium oxichloride and zirconium $n$-propoxide), also the experimental design for the digestion process of these samples were different.

Similar $\mathrm{Zr}$ content were obtained from different templates (cedar and pine) when the infiltration agent (zirconium $n$-propoxide) is the same for the two samples. 


\section{Acknowledgements}

The authors thank to the Ministerio de Ciencia e Innovación for supporting this study (Projects CTQ2009-07858) and also the Junta de Andalucia.

\section{References}

[1] G. Hanrahan and K. Lu, "Application of Factorial and Response Surface Methodology in Modern Experimental Design and Optimization," Critical Reviews in Analytical Chemistry, Vol. 36, 2006, pp. 141-151. doi:10.1080/10408340600969478

[2] P. E. Smith and E. A. Arsenault, "Application of Factorial and Response Surface Methodology in Modern Experimental Design and Optimization," Talanta, Vol. 48, 1996, pp. 1207-1268. doi:10.1016/0039-9140(96)01882-6

[3] K. J. Lamble and S. J. Hill, "Microwave Digestion Procedures for Environmental Matrices, Critical Review," Analyst, Vol. 123, 1998, pp. 103-133. doi:10.1039/a800776d

[4] I. V. Kubrakova and E. S. Toropchenova, "Microwave Heating for Enhancing Efficiency of Analytical Operations (Review)," Inorganic Materials, Vol. 44, 2008, pp. 1509-1519. doi:10.1134/S0020168508140069

[5] H. M. Kinston and S. J. Haswell, "Microwave-Enhanced Chemistry, Fundamental, Sample Preparation and Applications," American Chemical Society, Washington DC, 1997.

[6] C. Bosch Ojeda and F. Sánchez Rojas, "Sample Dissolution for Elemental Analysis/Microwave Digestion," Encyclopedia of Analytical Chemistry, 2nd Edition, Elsevier, 2005, pp. 153-163. doi:10.1016/B0-12-369397-7/00540-9

[7] M. Luo, J. Gao, G. Qiao and Z. Jin, "Synthesis of Wood-Derived Ceramics from Biological Templates," Progress in Chemistry, Vol. 20, 2008, pp. 989-1000.

[8] H. Sieber, J. Cao, C. R. Rambo and P. Greil, "Manufacturing of Porous Oxide Ceramics from Bioorganic Preforms," Ceramic Engineering and Science Proceedings, Vol. 23, 2002, pp. 175-181. doi:10.1002/9780470294758.ch20
[9] M. Singh and B. M. Yee, "Reactive Processing of Environmentally Conscious, Biomorphic Ceramics from Natural Wood Precursors," Journal of the European Ceramic Society, Vol. 24, 2004, pp. 209-217. doi:10.1016/S0955-2219(03)00244-9

[10] J. Cao, C. R. Rambo and H. Sieber, "Preparation of Porous $\mathrm{Al}_{2} \mathrm{O}_{3}$-Ceramics by Biotemplating of Wood," Journal of Porous Materials, Vol. 11, 2004, pp. 163-172. doi:10.1023/B:JOPO.0000038012.58705.c9

[11] J. Cao, O. Rusina and H. Sieber, "Processing of Porous $\mathrm{TiO}_{2}$-Ceramics from Biological Preforms," Ceramics International, Vol. 30, 2004, pp. 1971-1974. doi:10.1016/j.ceramint.2003.12.180

[12] J. Cao, C. R. Rambo and H. Sieber, "Manufacturing of Microcellular, Biomorphous Oxide Ceramics from Native Pine Wood," Ceramics International, Vol. 30, 2004, pp. 1967-1970. doi:10.1016/j.ceramint.2003.12.181

[13] C. R. Rambo, J. Cao and H. Sieber, "Preparation and Properties of Highly Porous, Biomorphic YSZ Ceramics," Materials Chemistry and Physics, Vol. 87, 2004, pp. 345-352. doi:10.1016/j.matchemphys.2004.05.031

[14] C. R. Rambo, J. Cao, O. Rusina and H. Sieber, "Manufacturing of Biomorphic (Si,Ti,Zr)-Carbide Ceramics by Sol-Gel Processing," Carbon, Vol. 43, 2005, pp. 1174-1183. doi:10.1016/j.carbon.2004.12.009

[15] Statgraphics Plus (version 5.1), Reference Manual, Manugistics: Rockville, MD, 1992.

[16] Physical Electronics, Multitechnique ESCA Reference Manual for the PCACCES Software Version 6.0; Physical Electronics: Minneapolis, USA, 1995.

[17] M. Nechar, M. F. Molina and J. M. Bosque-Sendra, "Application of Doehlert Optimization and Factorial Designs in Developing and Validating a Solid-Phase Spectrophotometric Determination of Trace Levels of Cadmium," Analytica Chimica Acta, Vol. 382, 1999, pp. 117-130. doi:10.1016/S0003-2670(98)00768-5

[18] L. M. Costa, S. L. C. Ferreira, A. R. A. Nogueira and J. A. Nóbrega, "Use of Factorial Design for Optimization of Microwave-Assisted Digestion of Lubricating Oil," Journal of the Brazilian Chemical Society, Vol. 16, 2005, pp. 1269-1274. 